\title{
LA EDUCACIÓN SUPERIOR CUBANA HACIA NUEVOS RETOS EN EL ACTUAL MILENIO. PROPUESTA EDUCATIVA PARA EL DESARROLLO DE VALORES COMUNICATIVOS Y DE IDENTIDAD EN ESTUDIANTES NO HISPANOHABLANTES QUE CURSAN ESTUDIOS EN CUBA
}

\author{
María Caridad Calvo Vázquez \\ (Universidad de Matanzas "Camilo Cienfuegos". Cuba)* \\ maria.calvo@umcc.cu \\ Rebeca de Armas Marrero \\ (Universidad de Matanzas "Camilo Cienfuegos". Cuba)** \\ rebeca.dearmas@umcc.cu \\ Milagros Agripina Catalá Llinás \\ (Universidad de Matanzas "Camilo Cienfuegos". Cuba) (*** $^{* *}$ \\ milagros.catala@umcc.cu
}

Recibido: 19/07/2012 Aceptado: 15/10/2012

\section{Resumen}

La Educación Superior cubana está enfrascada en un constante proceso de perfeccionamiento de sus vías de recepción e inserción en la arena educativa internacional. Para contribuir al logro de este objetivo un equipo de profesores que imparten idioma español en el Curso Preparatorio en la Universidad de Matanzas Cuba, ha elaborado una propuesta educativa para el desarrollo de valores comunicativos y de identidad en los estudiantes no hispanohablantes.

* Doctora en Ciencias Pedagógicas. Universidad de Matanzas "Camilo Cienfuegos". Cuba.

** Profesora de Español como Lengua Materna, Segunda Lengua y Lengua Extranjera.

Licenciada en Educación: Especialidad Español y Literatura (Universidad de las Ciencias Pedagógicas Juan Marinello, Ciudad de Matanas, República de Cuba, 1984).

Master en Ciencias de la Educación Superior: Mención Docencia Universitaria e Investigación Educativa (Universidad de Matanzas “Camilo Cienfuegos”- 2006).

Profesora Auxiliar del Departamento de Español, Universidad de Matanzas Camilo Cienfuegos, (UMCC).

*** Licenciada en Educación. Universidad de Matanzas "Camilo Cienfuegos”. Cuba. 
El trabajo en esta dirección con jóvenes no hispanohablantes se ha venido desarrollando en el departamento de español durante años de forma aleatoria con ejercicios gramaticales y de expresión oral y escrita. Por lo que se pretende mostrar las posibilidades que tiene la disciplina Idioma Español y específicamente las habilidades de comprensión auditiva y comprensión de lectura para desarrollar los valores, específicamente el de la identidad y elaborar una propuesta de trabajo que contribuya a ello.

\section{Palabras claves}

Curso Preparatorio - Español - Cuba - No hispanohablantes - Valores.

\section{Abstract}

The Cuban Higher Education is constantly improving its reception and insertion ways worldwide. As a contribution to the fulfillment of this goal, a Spanish language professors' team of the preparatory course at the University of Matanzas Camilo Cienfuegos in Cuba, has elaborated an educational proposal for the development of communicative and identity values in non-Spanish speaking students.

The Spanish language department has been randomly carrying out this kind of work with non-Spanish speaking students for years through grammar, oral and written expression exercises. Thus, this paper is intended to demonstrate the possibilities of the Spanish language discipline, and specifically the listening and reading comprehension abilities, in the fostering of values, namely identity, and thus elaborate a work proposal in that respect.

\section{Key words} Values.

Preparatory Course - Spanish language - Cuba - Non-Spanish speaking -

\section{Introducción}

La globalización y el acelerado desarrollo de la ciencia y la tecnología, han llevado a que el mundo se convirtiera en escenario de hechos muy diversos: construcciones de valiosas propiedades, monumentos históricos y de arte, la desaparición de vidas humanas, plantas y animales y la aparición de la realidad virtual, entre otros. Esos avances científicos y tecnológicos que crecen aceleradamente llevan consigo beneficios para unos y perjuicios para muchos. El deterioro ideológico aumenta y surgen nuevas enfermedades y epidemias que devastan a la humanidad.

Todo lo antes planteado está ocasionando profundas transformaciones en las percepciones del mundo, así como en los valores que orientan la conducta humana.

A pesar de las bondades que dice tener el nuevo orden económico, muchos también reconocen que éste es injusto, pues se está imponiendo a los pueblos sin atender a las diferencias étnicas, culturales y de tradición de gran 
cantidad de países. Así, el tema de la identidad adquiere suma vigencia en las condiciones que se presentan en el mundo actual; donde el hombre, como ente activo de la sociedad, se da a la búsqueda de su propio bienestar, acosado por problemas que van desde la aguda situación económica hasta la elaboración de proyectos que proponen la homogeneización ideológica de la sociedad mundial como reflejo de la unipolaridad del mundo y que conlleva al repliegue ideológico de las culturas nacionales y una nueva interpretación de la historia.

En medio de este agitado panorama mundial se mueven las universidades, con contradicciones internas en cuanto a la propia concepción del profesional que deben formar, pues los graduados universitarios son los llamados a ser los líderes que dirigirán el desarrollo político, económico y social del futuro.

Las universidades, centros de investigación y pensamiento por excelencia, están en el deber de buscar y promover opciones para el futuro. Ello explica la alta misión asumida por éstas de graduar profesionales que, junto con la consolidación de los valores ciudadanos, tengan una sólida preparación que les permita adaptarse con mayor rapidez y eficiencia a los cambios tecnológicos y a la vez, mayor versatilidad para su ubicación laboral. Por lo tanto, es imprescindible, lograr una formación integral en el profesional universitario.

La Universidad desarrolla su labor educativa ubicando en primer plano no solo los conocimientos y las habilidades que se deben formar y desarrollar en los estudiantes, sino también los valores como componente clave de su personalidad, lo cual supone, no solo definir en los planes de estudio los objetivos educativos que se aspiran alcanzar; sino instrumentar las vías o campos de acción, que permitan materializar este empeño.

La Educación Superior está enfrascada en un constante proceso de perfeccionamiento y los resultados positivos que se derivan de ello son una muestra fehaciente.

En su acepción más amplia, educar significa socializar, es decir, transformar al educando en un ser social, en parte constitutiva de una comunidad humana particular, paso imprescindible y único modo posible para hacerlo representante y partícipe del género humano. (Fabelo, Corzo, 2003. P: 83).

Esto hace que Cuba comparta experiencias y conocimientos con otras instituciones y estudiosos del mundo para elaborar políticas y programas de educación eficaces. De igual manera forma los profesores universitarios cubanos trabajan y cooperan con universidades de otros países. Por consiguiente, las probadas muestras de entrega de estos han contribuido a que Cuba sea elegida por muchos de ellos para capacitar a sus futuros profesionales.

Por otra parte, la autoridad que ha alcanzado el país en la educación, la salud y otros sectores, así como los convenios de diversa índole con diferentes estados, las relaciones con muchos países y la ayuda internacionalista que se ofrece; han planteado, desde el año 1976, la necesidad de incluir la enseñanza de nuestra lengua para jóvenes que llegan de disímiles partes del mundo para recibir de forma práctica los conocimientos de la misma. 
La Universidad de Matanzas, asume esta responsabilidad a partir del año 1983 en que se crea la Facultad Preparatoria. El estudiante que recibe este curso preparatorio intensivo, no egresa como especialista, pero sí debe adquirir hábitos, habilidades y conocimientos en el Idioma Español como lengua extranjera y en las asignaturas de formación general vinculadas a las especialidades que cursarán.

Estos estudiantes proceden de países con diferentes lenguas, tradiciones, costumbres, religiones, sistemas políticos, económicos y sociales. Para la inmensa mayoría constituye el primer encuentro con un medio idiomático hispánico y con características que difieren de las de sus países de origen. Por estas razones, el reto que deben vencer no es solo conocer la lengua, sino enfrentarse a una visión ante la vida diferente de la suya, tienen que intercambiar costumbres con los cubanos y con sus compañeros y adaptarse a su nueva realidad.

Es por ello que la disciplina Idioma Español, además de dar a conocer, de forma práctica, los principios y estructuras de la lengua, así como el léxico, que les permita la competencia comunicativa en dicho idioma, desarrolla un conjunto de influencias educativas dirigidas a la esfera motivacional e intelectual de la personalidad de manera simultánea, para así contribuir al desarrollo de actitudes y sentimientos que se correspondan con los valores del género humano.

El tema de los valores y de la identidad cobra hoy una importancia primordial para los destinos de la humanidad; de ahí que se plantee la necesidad de potenciarlos dentro de las asignaturas de los currículos, y en el caso particular de la enseñanza de español a estudiantes no hispanohablantes, se toman como punto de partida las habilidades de comprensión auditiva, expresión oral y comprensión de lectura para afianzar en ellos el desarrollo de los valores identitarios, pues una persona que no se respete y se estime a sí misma y a sus raíces, no puede comprender lo que significa el respeto por los demás. En la declaración de La Habana, en la Primera Reunión Intergubernamental del Proyecto Regional de Educación para América Latina y el Caribe, celebrada en el 2003, la UNESCO en dos de sus artículos plantea: La necesidad de promover una educación a lo largo de toda la vida en múltiples e interactivos ambientes humanos y educativos, centrada en una educación en valores como núcleo de la formación de la personalidad y que promueva aprendizajes orientados a posibilitar el ser, el hacer y conocer y a favorecer la convivencia humana, asumiendo como factor positivo nuestra rica diversidad étnica y cultural.

Nuestra educación debe reconocer y respetar la diversidad y afianzar cada vez más, los valores de la lengua materna, la cultura, la historia, la literatura y la identidad nacional. Es responsabilidad de los gobiernos y de las sociedades hacer todos los esfuerzos para que las diferencias individuales, sociales, económicas, étnicas, de género y de lengua, no se transformen en desigualdad de oportunidades, o en cualquier forma de discriminación. Es necesario propiciar el 
desarrollo integral de todos los estudiantes, asumir la convivencia y el pluralismo lingüístico, multiétnico y cultural, de acuerdo con las tradiciones de cada nación.

Por otra parte, la Comisión Internacional para la Educación en el siglo XXI de esa misma organización, opina que los cuatro pilares de la educación deben atender a los principios siguientes:

Aprender a vivir juntos.

Aprender a conocer.

Aprender a hacer.

Aprender a ser.

Con semejante postura se refuerza la idea de que las reformas educativas deben revolucionar las formas de enfocar los aprendizajes que hoy se generan en las escuelas.

Por lo tanto se debe lograr que los estudiantes:

Aprendan a convivir, a relacionarse con los demás modos de comportamientos aceptables socialmente y deben aprender y enseñar los suyos.

Aprendan a conocer la realidad en que se desenvuelven y se desenvolverán en el futuro.

Aprendan a hacer mediante un conjunto de estrategias y habilidades que los lleve a la creación de un mundo mejor.

Aprendan a conocerse a sí mismo, desarrollando la autovaloración, la autoestima, lo que proporciona que la persona pueda influir sobre sí misma.

El estudio de esta problemática y el reto que constituye para la disciplina Idioma Español desarrollar una labor educativa con jóvenes de todas las latitudes y por ende de distintas culturas, ha motivado a llevar a cabo esta investigación, tomando como punto de partida las habilidades comprensión auditiva, expresión oral y comprensión de lectura, a trabajarse en la enseñanza del idioma para desarrollar los valores, específicamente el de la identidad y elaborar una propuesta de trabajo que contribuya a ello.

La pertinencia de esta propuesta radica en que podrá favorecer la labor educativa que se viene desarrollando en los diferentes Cursos Preparatorios en Idioma Español del país, donde se preparan los estudiantes no hispanohablantes para insertarse en una sociedad que contempla la educación multi e intercultural con igualdad de derechos para todos, y para posteriormente, poder integrarse a cualquier sociedad.

\section{Desarrollo.}

El trabajo con estudiantes de diversas latitudes y disímiles formaciones sociales nos permitió determinar la existencia de una situación problémica susceptible de ser investigada para aportar soluciones que tributaran al fortalecimientos de lazos de camaradería, hermandad y colaboración mutua, en aras de minimizar manifestaciones de individualismo, irrespeto a la identidad cultural 
del otro, y las burlas, todo lo cual limita el respeto a la otredad. De ahí que se consideró pertinente la necesidad de afianzar el desarrollo de los valores de la identidad cultural en los estudiantes no hispanohablantes del Curso Preparatorio en Idioma Español de la Universidad de Matanzas "Camilo Cienfuegos".

Para ello tomamos como referentes teóricos y prácticos el trabajo que se hace con la expresión oral, la comprensión auditiva y la comprensión de lectura, así como el resultado aportado por investigaciones realizadas por profesores del colectivo pedagógico del departamento de Español de la citada Universidad: L. Sáez (1999); M.E. Aguilera (2000); R.E. Alfonso (2002-2008); L. Belismelis (2003); M.C. Calvo (2004-2011); M. Catalá (2005); entre otros.

El tema de los valores, su formación y desarrollo ha sido una inquietud constante del ser humano porque este al nacer llega a un mundo en el cual la cultura tiene establecido un conjunto de significados y de valores. A medida que se desarrolla una persona y acorde con la sociedad en que vive, escogerá como bueno o malo, positivo o negativo, justo o injusto, útil o inútil, cada fenómeno de su realidad.

Pero, ¿cómo educar y desarrollar valores en estos jóvenes que viven a veces en una sociedad esencialmente contradictoria en la mayoría de los casos?, ¿cómo desarrollar un razonamiento moral, una perspectiva de justicia en ellos que en número considerable viven en situaciones injustas de marginación social o situaciones de violencia en el propio seno de la familia?, ¿cómo hablar del valor de la dignidad y de la igualdad de las personas ante situaciones sociales claramente discriminatorias por razones económicas, de sexo o raza?, ¿cómo ir a contracorriente de los modelos que los medios de comunicación de sus países transmiten de forma mucho más eficaz e influyente que lo que lo puede la vida tan corta que han llevado entre los cubanos?, ¿cómo hacerlos comprender que lo autóctono, su conservación y defensa va a ser la única forma de luchar contra la desaparición de las identidades, lo cual nos lo impone la globalización neoliberal?.

Tener valores es apreciar en alto grado los elementos de la cultura nativa, las relaciones humanas, a las personas, determinados comportamientos morales que afectan al individuo, al hogar, la escuela y la sociedad en general.

Aprender un idioma no es adquirir gran cantidad de reglas, ni vocabulario, sino saber cómo usar estos. El alumno debe, paulatinamente: comprender, hablar, leer, y escribir porque: nada debe hablarse si no se ha oído, nada debe leerse si no se ha hablado, nada debe escribirse si no se ha leído.

El lenguaje es un vehículo por excelencia de trasmisión de la cultura, por lo tanto, la lengua, dentro de cada contexto socio cultural es, a su vez, un depositario verbal y discursivo de los diferentes niveles de la identidad cultural.

Tomando en consideración que los estudiantes en un curso académico deben apropiarse del sistema fónico del idioma español, de las diferentes estructuras morfosintácticas y de un determinado léxico, la enseñanza de esta 
disciplina está estructurada a fin de que los conocimientos puedan aplicarse de forma inmediata.

La disciplina Idioma español tiene un carácter práctico, aún cuando transmite al estudiante las bases conceptuales necesarias.

Ser capaz de comprender un texto oral es ser capaz de interpretar lo que quiere decir quien lo emite.

Para ello no es suficiente con entender todas las palabras y expresiones que componen el texto porque en la comprensión auditiva y lectora entran en juego otras habilidades, tales como la de relacionar lo que se oye con lo que se sabe acerca del tema y de la situación. No es necesario porque el desconocimiento (o en su caso, la falta de audición o recepción) de determinados fragmentos del texto suelen ser subsanados mediante esas otras habilidades.

El proceso de comprensión pone en marcha un complejo engranaje de habilidades que van desde el reconocimiento de elementos de la cadena acústica (identificación, discriminación y segmentación de las unidades significativas que componen el discurso) pasando por la selección de los sonidos, palabras, expresiones e ideas reconocidas para agruparlas en unidades coherentes y significativas hasta la interpretación de todos estos elementos para darles una estructura sintáctica y un valor comunicativo. Además, el oyente anticipa el discurso que el hablante va emitiendo, puede inferir significados a través de elementos no lingüísticos o paralingüísticos, o retiene información que se pueda considerar relevante para guardarla en la memoria y luego poderla utilizar para interpretar otros fragmentos del discurso.

Cuando se escucha en la lengua materna, se echa mano de todas estas habilidades de decodificación porque ya se han automatizado. Estos hábitos que el oyente nativo posee en su propia lengua y que usa de manera inconsciente, no siempre los alumnos los trasladan al proceso de escucha en la nueva lengua, al sentirse bloqueados por la constante búsqueda de significados.

Los hábitos correctos de lectura de la lengua materna se transfieren a la lectura en lengua extranjera, después que se han formado en la lengua materna. Este es el caso de los mecanismos de lectura tales como: leer por grupo de palabras, inferir los significados de palabras poco importantes, leer con rapidez, leer para sí sin vocalizar y otros. Pero también se transfieren hábitos incorrectos cuando se tienen; aprender a leer en una lengua extranjera ayuda a corregir las deficiencias que se tienen, así como a desarrollar los mecanismos de lectura en la lengua materna. El esfuerzo y la concentración necesarios para leer en el idioma extranjero ayudan a formar o a fortalecer los hábitos de atención a las formas en una y otra lengua. La adquisición del vocabulario y su aplicación consciente en la lengua extranjera mediante la lectura, crea condiciones favorables para la adquisición de palabras nuevas en la lengua materna, así como para comprender más profundamente las características del vocabulario en el idioma. Incluso se pueden aprender en lengua extranjera mecanismos que no se tengan en la materna, como pueden ser la lectura a saltos y la jerarquiza- 
ción de las ideas principales y secundarias. Estos mecanismos se revierten a la lengua materna.

La tarea didáctica consistirá en desarrollar esas estrategias, en hacerlas conscientes y en potenciar su uso.

En el proceso de enseñanza de lenguas extranjeras es necesario desarrollar por igual los aspectos de la actividad verbal. La lengua oral (que incluye la comprensión auditiva) es a la vez objetivo, contenido y vehículo de enseñanza de la pronunciación, la gramática y el vocabulario.

Como se ha dicho, este proceso requiere que se preste atención a cada uno de sus dos componentes por separado, pero que se ejerciten en estrecha correlación, ya que ambos son igualmente importantes como base para los otros dos aspectos de la actividad verbal (la lectura y la escritura) los que están estrechamente vinculados con el habla interior. Esto significa que si los alumnos desarrollan las habilidades de escuchar la lengua extranjera y pronunciarla correctamente, están en mejores condiciones para leerla y escribirla.

\section{Los niveles de comprensión auditiva y los procedimientos para evaluarlos}

La experiencia práctica ha demostrado que la comprensión tiene un carácter escalonado: se consideran tres(o cuatro) niveles de comprensión, a saber:

- $\quad$ Fragmentario (que algunos especialistas no consideran un nivel de comprensión), cuando solo se entienden palabras aisladas.

- Global o comprensión incompleta, cuando se comprende aproximadamente un $35 \%$ del contenido del texto escuchado. Es cuando se puede dar una idea general de lo que se ha escuchado, sin entrar en detalles

- Total o detallada, cuando se asimila al menos el $75 \%$ de lo escuchado. En este caso se puede decir no sólo de qué trata el texto, sino también sus detalles.

- $\quad$ Crítico, cuando la comprensión alcanza el $100 \%$ de los elementos que componen el texto. Son capaces aquí de comprender no solo el texto en sí mismo, sino también la intención del autor.

Para comprobar los diferentes niveles de comprensión se pueden emplear diversos procedimientos de control de acuerdo con las posibilidades de los estudiantes. El nivel fragmentario no tiene sentido comprobarlo pues se trata de un estado inferior previo a la verdadera comprensión. Para comprobar el nivel de comprensión global se utilizan los ejercicios de verdadero / falso en los que se pueden introducir algunas variantes tales como signos (más y menos) o bien incluir una tercera posibilidad "no dice", cuando se incluye una afirmación que no es verdadera ni falsa. Para este nivel son también válidos los ejercicios de selección múltiple.

Para controlar el nivel de comprensión total o detallada se pueden aplicar ejercicios en los que se llenan los espacios en blanco en la forma escrita del 
mismo texto. Se puede graduar la dificultad eliminando las palabras de acuerdo con una progresión que puede ser la siguiente cada 11 palabras, cada 7 palabras, cada 3 palabras. Este nivel se sugiere comprobar también mediante preguntas sobre el texto, que se admitiría responder en lengua materna a fin de no afectar la comprobación de comprensión, también se puede solicitar de los alumnos que digan el plan del texto oído o a la inversa, que lo reconstruyan a partir de palabras claves.

Esta capacidad se ejercita mediante una doble vía de procedimientos:

Los procedimientos llamados "desde arriba", es decir, lo que el oyente conoce acerca del tema, de la situación particular y de la realidad en general, que actúan como una luz que ilumina todo el texto y contribuye a su adecuada interpretación. Es lo que podríamos describir como "aquello que el cerebro dice a los oídos".

Los procedimientos "desde abajo", aquellos que trabajan a partir de "lo que los oídos le dicen al cerebro".

Ambos procedimientos intervienen en la comprensión auditiva de forma simultánea y en colaboración.

\section{Propuesta Metodológica para afianzar el desarrollo de los valores de la identidad cultural en los estudiantes de la Preparatoria en Idioma Español a través de la expresión oral, la comprensión auditiva y la comprensión de lectura.}

Seguidamente se propone un sistema de ejercicios para reafirmar la identidad cultural y potenciar el desarrollo de sus valores a través de la expresión oral, la comprensión auditiva y la comprensión de lectura, lo que favorecerá el vínculo entre lo afectivo y lo cognitivo y les permitirá la modificación de una realidad dada.

La propuesta tiene como base la concepción del aprendizaje como un proceso activo de creación y recreación del conocimiento en una relación estudiante / estudiante, estudiante / profesor, a través de ejercicios colectivos que propicien el intercambio y la confrontación de opiniones.

Estas tareas docentes educativas forman un sistema de ejercicios, problemas o situaciones encaminadas a la realización de habilidades que se quieren desarrollar en el estudiante. En ellas se tienen en cuenta los componentes del proceso docente educativo: objetivos, conocimientos, métodos y procedimientos, habilidades, valores, modos de actuación y evaluación; todos ellos contribuyen a la adquisición de conocimientos de la lengua y la cultura, (esta última no solo la cubana sino las que interactúan en su colectivo), propiciándose la participación activa de los estudiantes como sujetos activos del proceso. Es pertinente considerar la definición aportada por J.L Rodríguez (2000), sobre los niveles que se toman en consideración en las diferentes unidades que conforman el programa. Este autor los define de la siguiente forma: 
Nivel individual: "la correspondencia entre los rasgos psicosociales definitorios de la personalidad del individuo que establecen una doble relación de continuidad/ discontinuidad entre este y el resto de los seres humanos que lo rodean. Está determinado por el conjunto de características esenciales y socialmente trascendentes que definen al individuo;

Nivel sectorial: conjunto de rasgos psicosomáticos comunes que identifican a un grupo de individuos sobre la base de la semejanza en la actividad humana que realizan. El hecho de compartir una misma actividad (económica, social, productiva o de servicio), moldeando en los seres humanos aspectos tales como: la apariencia física, el comportamiento, las semejanzas en los conocimientos y las acciones compartidas, las preferencias, etc. En ambos casos lo espacial y lo temporal son importantes.

Nivel territorial: conjunto de rasgos de carácter psicosocial comunes que son compartidos por un grupo humano que vive en un territorio. Puede ser ciudad, región, país o grupo de países. De lo espacial más pequeño a lo más grande. Entre los rasgos comunes que comparten están: una o varias lenguas, una o varias religiones, tradiciones históricas, convicciones político ideológicas, valores, entre otros. Se marca el énfasis en la ruptura de una con respecto a otras.

Nivel universal: conjunto de rasgos psicosociales que atañen a la esencia común del ser humano con independencia de la existencia de los niveles anteriores y sin que necesariamente entren en contradicción con ellos. Se refleja en producciones humanas como el arte y tiene un punto de enlace con lo individual. Es la proyección socializada de lo individual en la más alta expresión de la identidad". (Rodríguez, J.L., 2000).

En cada unidad se comportará de la manera siguiente:

\begin{tabular}{|l|l|}
\hline Unidades & $\begin{array}{l}\text { Niveles de tratamiento de la identidad } \\
\text { cultural que serán tratados en espiral }\end{array}$ \\
\hline I El encuentro de los estudiantes & Introducción del nivel individual. \\
\hline II ¿Qué haces? & $\begin{array}{l}\text { Despliegue del nivel individual / } \\
\text { grupal. }\end{array}$ \\
\hline III Nuestras actividades en la Facultad & Despliegue del nivel grupal/ sectorial. \\
\hline IV Los compañeros conversan & Interacción de diversos niveles. \\
\hline V La familia & Nivel contrastado y enriquecido. \\
\hline VI La atención médica en Cuba & $\begin{array}{l}\text { Nivel sectorial y nacional de la } \\
\text { otredad/ contraste por extensión } \\
\text { y asimetría con su realidad. }\end{array}$ \\
\hline
\end{tabular}


En las demás unidades del I Semestre interactúan todos los niveles.

En el II Semestre se recicla en espiral lo aprendido en el I Semestre pero ahora son más argumentativas las tareas, con casos de debates problémicos.

\begin{tabular}{|l|l|}
\hline Unidades & $\begin{array}{l}\text { Niveles de tratamiento de la identidad } \\
\text { cultural que serán tratados en espiral }\end{array}$ \\
\hline I Cuba: la mayor isla del Caribe & Nivel territorial de la otredad. \\
\hline II La Universidad & Nivel sectorial/ grupal compartido \\
\hline III Figuras legendarias & Nivel individual contrastado. \\
\hline IV La mujer & $\begin{array}{l}\text { Nivel individual/familiar/ sectorial/ } \\
\text { territorial/nacional/ universal } \\
\text { contrastado. }\end{array}$ \\
\hline V Cuba y su cultura & $\begin{array}{l}\text { Desde el nivel individual hasta } \\
\text { el nacional. }\end{array}$ \\
\hline
\end{tabular}

Las unidades VI y VII trabajarán el nivel universal ya que se refieren a la Ciencia y la Técnica y a la paz y la amistad.

Características de la propuesta de intervención psicopedagógica para potenciar el desarrollo y la consolidación de los valores de la identidad cultural a través de la comprensión auditiva y la lectora

1. Mostrar los aspectos significativos de las culturas que interactúan, en cada momento.

2. Emplear ejercicios y textos que posibiliten la autorreflexión sobre su persona y las de otras culturas, lo que se contribuirá al desarrollo de un aprendizaje desarrollador (Desarrollar un pensamiento que permita valorar adecuadamente la realidad social en que se desenvuelve, su formación a partir del compromiso individual y social que asumirán como profesionales).

3. Emplear juegos didácticos.

4. Emplear técnicas participativas.

5. Evaluar lo que han compartido e incorporado de otras culturas a su personalidad, desarrollando así el pensamiento crítico.

\section{Propuesta de sistema de ejercicios.}

1. Escucharemos una conversación entre tres personas que se presentan entre sí. Cuando termine la audición nos reuniremos por países y un estudiante presentará al resto de los integrantes de su país. (Luego representaremos la misma). 
2. Leen un artículo periodístico sobre la conservación y cuidado del medio ambiente que se lleva a cabo en nuestro país. Cada país explicará cómo se lleva a cabo este programa en el suyo y cómo contribuirá a él. Se intercambiarán los criterios y consideraciones de los distintos integrantes del grupo.

Posteriormente cada cual dirá lo qué tomaría de la explicación de otro país porque le parece efectivo. Constituirán equipos mixtos y elaborarán un programa con este objetivo, considerando que ahora habitan en un país cuya responsabilidad es suya y al cual deben salvar.

3. En un sobre el profesor pondrá diversos sustantivos, verbos y adjetivos. El alumno que comience, saca del sobre la primera palabra e iniciará un cuento de la cuentística de su país que esté relacionado con esa palabra y le pasa el sobre al de al lado que intentará seguir con la historieta. El juego finalizará cuando el último alumno haya trabajado la última palabra. No hace falta que la historia sea real, lo importante es que cada palabra sea empleada con creatividad y cierta consecución.

4. Uno o dos alumnos expondrán una noticia hipotética publicada en su país. Los demás les harán preguntas al respecto y de ser posible él expondrá al final cómo dar solución a ese problema, según su punto de vista.

Las noticias deberán estar escritas aunque él la exponga. (También puede leerla).

5. Un alumno describe un juego deportivo. Los demás estarán atentos para agregarle lo que le falta al juego.

6. Los alumnos divididos por nacionalidades. Se les pide que imaginen un viaje en el tiempo y con este harán un recorrido por la historia de su país; desde la conquista o descubrimiento hasta la independencia o la fecha actual.

Luego se lo expondrán o leerán a sus compañeros.

7. La historia del descubrimiento, conquista y colonización de cada país es un aspecto que está lleno de dolor, sufrimiento pero también envuelto en misterios y además resulta interesante para todos. Sus compañeros han expuesto acerca de estos momentos tan importantes. ¿Pudiera representar algún aspecto que le haya impresionado y con el cual se haya sentido identificado por estar muy cercano a su historia? ¿Qué cree al respecto? ¿Qué elementos de estos momentos cree que haya influido en la idiosincrasia de su país y en el de alguno de sus compañeros? ¿Por qué?

8. Se reparten relatos relacionados con líderes universitarios entre los diversos grupos de alumnos por nacionalidades. Se propone su lectura, y luego la analizarán, teniendo en cuenta la guía. Por ejemplo:

- ¿Qué haría si fuese el personaje principal?

- ¿Qué ambientación cambiaría para ubicarlos en su pueblo o país? 
- ¿Qué elementos le hacen identificarse con este líder?

Luego se les pide que formen grupos mixtos para intercambiar los criterios y se presentará una dramatización del escogido por cada equipo.

9. Con una canción acerca de los niños, de la mujer, dedicada a las madres; se les puede pedir explicar cómo se aborda esta problemática en su país, y cada cual dará su punto de vista.

Al final escribirán sus propias impresiones, harán un dibujo o una redacción del tema abordado.

10. Versificando

Puede intentarse hacer un poema y el profesor inducirá que el tema de éste sea la paz, la convivencia pacífica, la amistad, la solidaridad, la protección de la niñez, el desarrollo sostenible u alguno de los problemas que aquejan al mundo y que deben resolverse.

11. Discuta con sus compañeros acerca de lo que sabe de sus respectivos países y qué piensa al respecto. Escriba un párrafo donde exprese qué aprendió de las otras culturas y qué consideración le merecen.

12. Los alumnos escucharán el siguiente diálogo entre tres estudiantes de diferentes países. Tania (cubana), Areolinda (caboverdiana) y Maimouna (nigerina):

Tania: _ ¡Muchachas!, iqué feliz soy! Aunque Carlos y yo vivimos hace tiempo juntos, el próximo mes nos casaremos.

Maimouna: _ ¿Y qué les llevaron de dote sus padres a tus padres?

Tania: _ ¿Dote? Bueno, Carlos les aseguró que me ayudaría y respetaría como lo ha hecho hasta ahora, ellos lo saben. Vivimos con ellos.

Maimouna:_ ¿ ¿Vivirán ahora en otra casa?

Tania: _No, en la misma pero estaremos legalmente comprometidos. ¿Entienden?

Maimouna: _ No mucho, cuando pidan mi mano yo no conoceré mucho a mi pareja porque el compromiso lo establecieron mis padres hace muchos años y sus padres les llevarán a los míos una cuantiosa dote que les garantizará mi bienestar futuro. Tiene que ser una gran dote porque pertenecemos a familias tradicionales y acaudaladas. Además entre el período en que se desarrolle mi noviazgo deberá construir o comprar una casa muy grande.

Areolinda: __ ¿Y en qué iglesia será la ceremonia?

Tania: _ No, lo haremos en el Palacio de los Matrimonios, aunque mis padres creen en Oshún y Las Mercedes, no asistimos a ninguna iglesia. Areolinda: _No entiendo cómo pueden darles nombres diferentes a las deidades, conozco a Las Mercedes pero no sé quién es Oshún.

Maimouna: _ Es porque profesas la religión cristiana... 
Tania: _ Recuerden que nosotros, los cubanos, somos una mezcla de muchas culturas y lo manifestamos en todas las acciones que realizamos. Maimouna y Areolinda: _ Es verdad.

Tania:_Areolinda, ¿ tu compromiso será como el de Maimouna? Areolinda: _ No, yo escogeré a la persona que será mi esposo y él a mí, pero sus padres tendrán que pedir mi mano, luego haremos una gran fiesta de familia, amigos y vecinos y fijaremos la fecha del matrimonio que será en una iglesia católica y habrá una gran fiesta también. Por supuesto nos iremos a vivir en nuestra propia casa.

Tania: _ ¡De qué forma tan diferente llegaremos las tres al matrimonio!

A continuación se dialogará con los estudiantes acerca de:

- Formas de realizarse los compromisos y matrimonio en sus países.

- La explicación de por qué se realizan así, en qué está basada la tradición.

- Si están de acuerdo o desacuerdo y por qué.

- Cuál escogerían ellos si les fuera posible.

13. Lea detenidamente el siguiente texto:

Un muchacho japonés, lleva 3 meses viviendo en el mismo cuarto con 1 cubano, 1 vietnamita, 1 senegalés, 1 burundés y 1 zambiano.

Al muchacho cubano le gusta gesticular mucho y mantener el contacto físico mientras habla en voz muy alta. Los demás compañeros, aunque no se manifiestan como él, ya se acostumbraron a su forma; pero el japonés, se aleja cuando le habla y no responde casi nunca a sus preguntas y cuando lo hace, son respuestas muy escuetas.

El cubano dice que él no comprende lo que le dice y que es un "bobo". Pero un día, el estudiante japonés lo sorprende desde su cama, interviniendo en la conversación. Su criterio es el más acertado, sin embargo no alzó la voz, ni la vista y sus miembros casi no se movieron para expresar una verdad contundente.

Responda:

a) ¿Qué cree al respecto?

b) ¿Conoce a alguna otra cultura que se manifieste igual?

c) ¿Cómo reaccionaría usted? ¿Por qué?

d) ¿Qué ha aprendido de la cultura cubana y de las otras culturas a la hora de dar criterios, opiniones?

e) ¿Incorporaría alguna de esas formas de actuar, diferentes a la suya, a su personalidad?

14. El profesor les planteará la siguiente situación:

Un estudiante cubano entra a la sala de computación donde están muchos estudiantes extranjeros y dice: 
“Calabaza, calabaza, cada uno pa'su casa y el que no tenga casa que se vaya pa' la plaza".

Preguntará:

a) ¿Qué entiende usted con esta expresión?

b) ¿Hay alguna frase que tenga significado parecido en su país?

La comprensión auditiva de una lengua extranjera es difícil porque requiere una intensa actividad lingüística, a saber que el alumno discrimine rápidamente los sonidos, los retenga mientras escucha una palabra, frase u oración y reconozca estas como unidades de sentido, lo cual se produce casi sin excepción en la lengua materna. Los alumnos realizan este proceso lentamente pues están ante todo conscientes de las formas lingüísticas que perciben por el oído. Poco a poco el habla interior va disminuyendo en la medida en que los tres analizadores comienzan a funcionar al unísono y conforman un sistema integrado, único, es decir, cuando el estudiante comienza a pensar en la lengua extranjera.

La enseñanza de la lectura en los cursos de lengua extranjera es, un objetivo de fundamental importancia; la lectura es el único aspecto de la actividad verbal que se puede continuar de modo independiente durante toda la vida, por lo que una vez que se adquieren sus mecanismos en el aula se pueden aplicar con constancia como fuente permanente de práctica lingüística y de ampliación cultural.

Estas habilidades permiten a los estudiantes apropiarse no solo del sistema de la lengua sino que contribuye a que se introduzca en su idiosincrasia porque aprender sobre el mundo extranjero y aprender a usar su lengua es algo más que formar hábitos o reproducir modelos de habla. Comprende una dimensión cognitiva del aprendizaje que se realiza mediante procedimientos de comparación, inferencia, interpretación, discusión y otras formas discursivas similares de negociar el significado de los fenómenos del mundo extranjero.

\section{Conclusiones.}

Por todo lo anteriormente expuesto se considera importante la incorporación en el trabajo docente educativo, de un sistema de actividades que parta de una estrategia de educación intercultural que abarque todas las dimensiones del conocimiento para facilitar el desarrollo de los valores comunicativos y de identidad en los estudiantes no hispanohablantes que cursan estudios en Cuba, estrechamente unido a la negociación de simetrías y asimetrías firmemente establecidas dentro de la cosmovisión de cada cultura.

Por la importancia que posee el tema abordado, ha sido objeto de múltiples investigaciones por parte de profesores que imparten la especialidad.

Es pertinente el desarrollo de valores comunicativos e identitarios en los estudiantes no hispanohablantes, de modo que se inserten con sus costumbres y todos los atributos de su lengua y cultura, en la sociedad cubana en la 
que vivirán por el período de 6 ó 7 años, y dentro de la que deben establecer relaciones interculturales.

Es necesario aprovechar todos los espacios de socialización para el establecimiento de relaciones multi e interculturales que tributen al enriquecimiento de idioma español que aprenden los estudiantes no hispanohablantes que cursan la Preparatoria en Cuba, con lo que se enriquecerá el patrimonio y acervo cultural de todos los participantes en el proceso.

\section{Referencias Bibliográficas}

- $\quad$ Aguilera, M.E. (2000). La Práctica Situacional Interactiva. Una vía para el desarrollo de la competencia comunicativa de los estudiantes de la Preparatoria de Español. Tesis en opción al título de Máster en Ciencias de la Educación Superior. CEDE. Universidad de Matanzas.

- $\quad$ Alfonso, R.E. (2002). Diagnóstico de las cualidades volitivas en el aprendizaje del español en estudiantes extranjeros. Propuesta psicopedagógica. Tesis presentada en opción al título de Máster en Ciencias de la Educación Superior. CEDE. Universidad de Matanzas.

- $\quad$ Alfonso, R.E. (2008). Estrategia didáctica para el desarrollo de la competencia cognitivocomunicativa-sociocultural en la enseñanza-aprendizaje del español como segunda lengua en la Preparatoria multicultural, con el empleo de las tecnologías de la información y las comunicaciones. Tesis de Doctorado. La Habana, Cuba.

- $\quad$ Antich de León, R., Gandarias Cruz, D., López Segrera, E. (1987). Metodología de la Enseñanza de la Lengua Extranjera. La Habana: Ed. Pueblo y Educación.

- Belismelis L. (2003. Estrategia para el diseño del Proyecto Educativo Multi e Intercultural del curso preparatorio de Lengua Española. Tesis en opción al título de Máster en Ciencias de la Educación Superior. CEDE. Universidad de Matanzas.

- Calvo, M.C. (2004). Propuesta de ejercicios en Páginas Web para la modalidad Semipresencial de la Asignatura Idioma Español I de Preparatoria. Tesis en opción al título de Máster en Ciencias de la Educación Superior. CEDE. Universidad de Matanzas, Cuba.

- Calvo, M.C. (2011). Estrategia didáctica para el desarrollo de la competencia lectora intercultural en los estudiantes no hispanohablantes del Curso Preparatorio en Idioma Español. Tesis de doctorado. La Habana, Cuba.

- Callejas, C.O. (2000). El enfoque comunicativo en la concepción del programa del curso de profundización para la enseñanza del español a extranjeros. Tesis de maestría. La Habana, Cuba.

- Catalá, M. (2005). Propuesta Pedagógica para desarrollar valores de la identidad en la Preparatoria en Lengua Española. Tesis en opción al título de Máster en Ciencias de la Educación Superior. CEDE. Universidad de Matanzas, Cuba.

- De Armas, R. (2006). Propuesta educativa para desarrollar valores de la comunicación en el idioma español con estudiantes extranjeros en la UMCC. Tesis en opción al título de Máster en Ciencias de la Educación Superior. CEDE. Universidad de Matanzas, Cuba.

- De Ansorena, A. (1996). Informe a la UNESCO de la Comisión Internacional sobre la Educación para el Siglo XXI. Barcelona, Paidós, Empresa Delors, Madrid: Santillana, UNESCO.

- $\quad$ López, M. (1998). Actividad Comunicativa y Expresión escrita. Revista Con luz propia. No. 3. La Habana, Mayo-agosto, 4-8. 
- Pérez, I. (2001). Hábitos de lectura en la actualidad. Algunas consideraciones. Revista Educación. No. 104. La Habana, Sep-Dic, 33-35.

- Porro, M., Báez M. (1987). Práctica del idioma Español. La Habana: Ed. Pueblo y Educación.

- Rodríguez, J.L. (2000). Estrategia pedagógica para el desarrollo del autocontrol de la comprensión y las expresiones interculturales en la formación de traductores e intérpretes. Tesis presentada en opción al grado de Doctor en Pedagogía y en Ciencias de la Educación. La Habana, Cuba.

- Sáez, L. (1999). Estrategia docente-educativa de la disciplina idioma español para el conocimiento del sí del estudiante extranjero de Preparatoria. Tesis en opción al título de Máster en Ciencias de la Educación Superior. CEDE. Universidad de Matanzas, Cuba. 